\title{
Common Complications during Hemodialysis Session; Single Central Experience
}

Habas El ${ }^{1 *}$, Rayani $A^{2}$, Alkanonie W', Habas A $^{4}$, Alzoukie E ${ }^{5}$, Razeik $S^{6}$, Alhabash $B^{7}$, Emssade ${ }^{8}$, El Marghani $\mathbf{A}^{9}$

${ }^{1}$ Consultant Physician, Medical Department, TCH, Tripoli University, Libya

${ }^{2}$ Consultant Pediatrician, Tripoli University, Libya

${ }^{3}$ Medical Intensive Care, Medical Department, TCH, Libya

${ }^{4}$ Medical Department, TCH, Libya

${ }^{5}$ Medical Department, TCH, Libya

${ }^{6}$ Medical Intensive Care, Medical Department, TCH, Libya

${ }^{7}$ Medical Department, Nephrology,TCH, Libya

${ }^{8}$ Medical Department, TCH, Libya

${ }^{9}$ Biotechnology Research Center (BTC), Libya

*Correspondling author: Elmukhtar Habas, Medical Department, Tripoli Central Hospital (TCH), Tripoli Medical College, Tripoli University, Libya

Received: December 03, 2018; Accepted: J anuary 11, 2019; Published: January 18, 2019

\section{Abstract}

Background: Hemodialysis (HD) is a renal replacement modality that widely used in End Stage Renal Disease (ESRD) therapy. HD complications occur during HD, post-HD session, and at long term.

Aim of the Study: To assess frequency of common complications that occur during HD-session.

Method and Patients: Study planned to assess the complications happened during HD-session for 335 patients. All patients had been informed about study aim. All patients included had not any evidence of HBV, HCV or HIV infection. Patient had their weight, blood pressure, pulse, Random Blood Sugar (RBS) and body temperature before they sat on HD-bed. Regular checkup of vital signs every 30 minutes. Any change of these parameters were recorded. Other parameters as hypoglycemic feature, hypotension, rigor, hotness and others were noted.

Statistical Analysis: After data collection and arrangement in Excel sheet of Microsoft Office version 16, frequency and average of the parameters are calculated by IBM-SPSS version 25 (SPSS, Chicago, IL, USA) statistical package.

Results: Three hundred thirty-five patients enrolled. They were 132 females and 203 male patients, aged $31-56$ years $(48 \pm 5.2)$, and weight range was 51$76 \mathrm{Kg}(66 \pm 3.4)$. There were 156 patients; 46 hypertensive, 62 diabetics, and 48 diabetics and hypertensive. The rest were not hypertensive or diabetic.

Vomiting reported in (61.8\%) of patients; during $1^{\text {st }}$ hour, vomiting occurred in $(40.9 \%)$ of patients. During $2^{\text {nd }}$ and at $3^{\text {rd }}$ hour of HD-session, patients had vomiting almost the same number during this time of HD session. Epigastric pain reported in (26.2\%), and vomiting with epigastric pain reported in (11.6\%) of patients. Epigastric pain and vomiting with raised pancreatic enzymes reported in $(1.8 \%)$ of patients.

Low random blood sugar (RBS) reported in (56.4\%) patients; during $1^{\text {st }}$ hour (29.2\%), only (3.3\%) of patients had low RBS with features of hypoglycemia. During the $2^{\text {nd }}$ hour of the HD-session $(15.8 \%)$ had low RBS and $(2.3 \%)$ had clinical feature of hypoglycemia. During $3^{\text {rd }}$ hour of HD-session, $(11.3 \%)$ of patients had RBS $\leq 60 \mathrm{mg} / \mathrm{dl}$, only $(1.8 \%)$ of patients had clinical features of hypoglycemia.

Hotness and normal body temperature noticed in (30.4\%) of patients. Hotness with increased body temperature without shivering reported (4.5\%), hotness, shivering and increased body temperature reported in $(14 \%)$ of patients.

During the $1^{\text {st }}$ half an hour $15.2 \%, 2^{\text {nd }}$ hour, $12.5 \%$ of patients, last 45 minutes $(8.3 \%)$ of patients had hypotension. Tachycardia reported in (28\%) of patients. Chest pain reported in $(2.2 \%)$ of patients, and only $(2 \%)$ of patients had ECG changes suggestive ischemic changes. Only (1.5\%) of patients had cardiac arrest. Tachypnea reported in (12.2\%).

Patients had HD-session via fistula were $(41.7 \%)$ of patients. Six patients had hematoma, two patients had infected fistula site. Other 193 had double lumens HD-catheter, (24.3\%) had permanent catheter, (75.7\%) had temporary HD-catheter. Evidence of infection as redness, discharge, pain reported. Fever and rigor reported in $(26.7 \%)$ patients. One, two lumens block reported in (8.9\%), (6.2\%) respectively. 
Conclusion: Vomiting is the commonest complication and low RBS Hotness and hypotension were not also uncommon. Early start of HD, better control of dialysate temperature, strict infection control, and regular vital signs on short time basis and using glucose containing dialysate solutions are major issues to minimize these acute HD complications.

Keywords: Hemodialysis complications; Intradialytic; Vomiting; Hypoglycemia; Hypotension

\section{Introduction}

ESRD is prevalent disease worldwide. A major public health problem can lead to considerable co-morbidity and mortality, and high expenditure by health services providers. Regular HD is the commonest mode of renal replacement treatment in comparison with peritoneal dialysis and renal transplantation all over the world [1,2]. It has been also reported by Blagg 2001, and Habas et al. 2012 that more than 500.000 patients worldwide, and about 250.000 patients in USA were on regular HD, and most of ESRD patients have three session of HD per week [3,4]. It had been estimated that at 2010, HDdependent patients were about two million [5], and at 2030, more than two million patients will be HD dependent ESRD [6].

Patients on regular HD develop many complications during the session of HD (Intradialytic), post-HD session, and have long-term complications $[3,4]$. The most common intradialytic complications of $\mathrm{HD}$ are, hypotension, vomiting, epigastric pain, hypoglycemia, chest pain, tachycardia, muscle cramps, cardiac arrest, shivering, hotness, epistasis, melena, hallucination, restlessness leg, allergic reaction and jaw lock [2].

In Libya, about 4000 patients have regular HD, while HD is the primary renal replacement therapy available in this country [7].

Up to our knowledge, there was not any study conducted to assess complications that occur during HD session. Therefore, this study was planned to assess the common complications occurring during HD session in patients on regular hemodialysis for more than three months and less than nine months.

\section{Statistical Analysis}

Data were collected and arranged at Excel sheet of Microsoft Excel version 16 program. The statistical analysis was conducted by IBM-SPSS version 25 (SPSS, Chicago, IL, USA) statistical package.

\section{Method and Patients}

Three hundred thirty-five patient enrolled in this study. All patients were ESRD on regular HD more than 3 months and less than nine months, mostly three sessions per week. They were 132 females and 203 male patients (Figure 1). Their age average $48 \pm 5.2$ (sem) with a range of 31 to 56 years. Weight average was $66 \mathrm{Kg} \pm 3.4$ with a range of 51-76 Kg. one hundred and six patients either hypertensive, diabetic or both diabetic and hypertensive $(46,62,48$ patients) respectively, 170 patients were not hypertensive or diabetic. All patients had 3 hours' HD session with mean of inter-dialytic weight increase of $2.3 \pm 5.4 \mathrm{Kg}$.

A case sheet for every patient for 6 sessions were prepared for the studied complications and given to duty doctor and technician to note them. Every patient his/ her weight, blood pressure, respiratory rate, temperature and pulse were taken before starting the dialysis session, and then every half an hour during the whole HD-session time.

The complications that studied are; hypotension, hotness, fever, tachy-bradycardia, chest pain, change in respiratory rate, muscle pain, spasm or cramps, vomiting, epigastric pain, hypoglycemia, chest pain, cardiac arrest, shivering, epistasis, restlessness leg, allergic reaction. HD- Catheter related problems as increased vein pressure, one or two lumens poor blood flow, obstruction of either of the lumen or the two lumens, and infection evidence at the entrance site of HD catheter.

\section{Results}

Vomiting during hemodialysis session reported in 207 patients (61.8\%) at different time of HD session. During the first hour, vomiting reported in 137 patients $(40.9 \%)$, at $2^{\text {nd }}$ hour 40 patients $(11.9 \%)$, and at $3^{\text {rd }}$ hour 30 patient $(8.9 \%)$. Epigastric pain reported by 88 patients $(26.2 \%)$. Vomiting with epigastric pain reported in 39 patients $(11.6 \%)$. Only 6 patients $(1.8 \%)$ had epigastric pain and vomiting had raised serum amylase and lipase.

Low RBS reported in 189 patients (56.4\%) in whole session. During $1^{\text {st }}$ hour of HD-session; 98 of these patients (29.2\%) had low RBS, and only 11 patients (3.3\%) had low RBS records and features of hypoglycemia. At $2^{\text {nd }}$ hour, 53 patients $(15.8 \%)$ had low RBS readings, and only 8 patients $(2.3 \%)$ had one or more clinical feature of hypoglycemic attack. During $3^{\text {rd }}$ hour of HD-session, 38 patients $(11.3 \%)$ had blood sugar $\leq 60 \mathrm{mg} / \mathrm{dl}$, and only 6 patients $(1.8 \%)$ had clinical features of hypoglycemia (Figures 2,3).

Hotness noticed by patients in 102 patients (30.4\%) with normal body temperature. Hotness with increased body temperature without shivering reported in $15(4.5 \%)$ patients, while hotness, shivering and increased body temperature reported in 47 (14\%) patients at least in one of the sessions.

\begin{tabular}{|c|c|c|}
\hline \multicolumn{3}{|c|}{ Sex distribution } \\
\hline 250 & & \\
200 & & \\
150 & & \\
100 & & \\
50 & & \\
\hline 0 & Female & \\
\hline
\end{tabular}




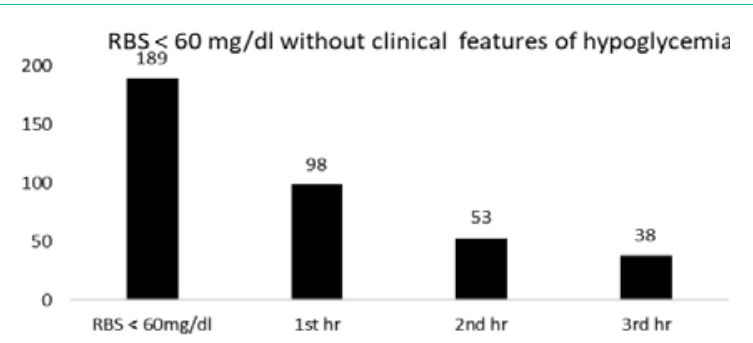

Figure 2: Total number of patients had random blood sugar (RBS $<60 \mathrm{mg}$ $\mathrm{dl}$ ), and number of patients had RBS $<60 \mathrm{mg} / \mathrm{dl}$ without clinical features of hypoglycemia each hour.


RBS $<60 \mathrm{mg} / \mathrm{dl}$ with hypoglycemia feature



2nd hr

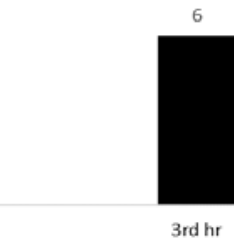

Figure 3: Total number of patients had RBS $<60 \mathrm{mg} / \mathrm{dl}$, and number of patients had RBS $<60 \mathrm{mg} / \mathrm{dl}$ and hypoglycemia clinical features each hour.

Hypotension during the first half an hour was recorded in 51 patients $(15.2 \%), 42$ patients had hypotension during the $2^{\text {nd }}$ hour of HD-time, and during the last 45 minutes, 28 patients (8.3\%) had hypotension. Tachycardia reported in 94 patients (28\%) (Figure 4). Chest pain reported in $21(2.2 \%)$ patients, while only 7 (2\%) patients had ECG evidence based ischemic changes. Cardiac arrest occurred only in 5 patients (1.5\%), and only 2 patients expired during first hour of CPR.

An increase in respiratory rate reported in $41(12.2 \%)$ patients, 24 patients improved spontaneously, 5 patients needed oxygen. Mild chest pain with increased respiratory rate reported by 12 patients, seven patients of them improved after reduction of blood flow and oxygen inhalation within half an hour from the onset of the chest pain.

Full features of acute allergic reaction reported only in 4 patients (1.2\%). Twitching of the face and jaw lock reported in 9 patients (2.6\%). Restless leg reported in 11 patients (3.3\%), and muscle cramp reported in 26 patients $(7.8 \%)$.

Patients had HD-session via fistula were 142 patients (41.7\%) (76 males and 66 females). Six patients had hematoma at the site of HDneedles insertion, two patients had infected fistula site.

Other 193 had double lumens HD-catheter. Out of these patients, 47 patients (24.3\%) had permanent catheter, and 146 patients $(75.7 \%)$ had temporary HD-catheter that inserted either at jugular, femoral or at subclavian veins.

Patients had HD via temporary HD-catheter during the period of the study were 146 patients. Out of the 146 patients, had temporary HD-catheter, 78 patients (53.4\%) had internal jugular HD-catheter,

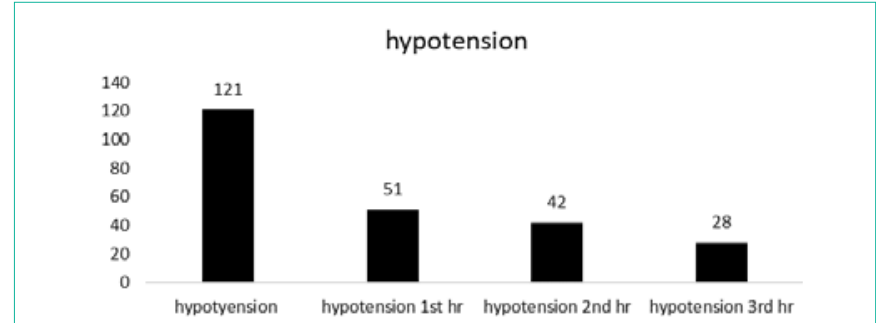

Figure 4: Total number of patients had hypotension and number of patients had hypotension each hour.

44 patients (30.1\%) had subclavian HD- catheter and 24 patients $(16.5 \%)$ had femoral catheter. Fever and rigor reported in 39 patients (26.7\%). Blockage of one lumen reported in 13 patients $(8.9 \%)$, double lumens blockage in 9 patients (6.2\%).

Out of 47 patients who had permanent HD- catheter, 6 patients (12.7\%) had clinical and investigatory evidences of infection. Infected catheter removed, and they continued HD via newly inserted temporary HD catheter.

\section{Discussion}

$\mathrm{HD}$ is the most common modality of renal replacement therapy. HD has been started at the earlier years of the previous century (1, 8). Most of ESRD patients if not all start HD as the first line of renal replacement therapy even if they have been planned for kidney transplantation. ESRD patients need usually to do HD from some time even if they are doing peritoneal dialysis. In many patients, HD started urgently, however some patients who had regular follow up and aware of their CKD problems, HD can be planned for them.

Although HD saves many patients' life, it can lead to major complications, disabilities and even death [9]. Libya as other countries in the world has CKD patients who are progressing to ESRD, and majority are started on HD directly $[10,11]$.

Long-term complications such as cardiovascular, respiratory, skin, central nerves system, musculoskeletal and vascular access are not uncommon [5]. Besides these long-term complications, there are complications occur during HD session either at the beginning of. And/or during the whole time of HD session [12-21].

This study had been conducted to assess common complications that happened at the start until the end of HD session. All the enrolled patients had not any significant cardiac diseases, and chronic liver diseases. They were not HBV, HCV and HIV infected patients.

Vomiting, Hypotension, hypoglycemia, hotness, rigor, infection, fever, HD access problems and other cardiovascular complications occurred.

Vomiting reported in 189 patients mainly during the $1^{\text {st }}$ hour of HD-session. Vomiting alone is one of the common complications occurs during the beginning of HD session [2]. It has been claimed that dialysis disequilibrium syndrome is a well-known cause of nausea and vomiting if the urea clearance is high. Furthermore, high dialysate sodium and low calcium concentration might have contributed to vomiting and nausea. In the current study, sodium in the dialysate was higher $5 \mathrm{mmol} / \mathrm{l}$ than patients' serum sodium, but dialysate calcium was the low. Despite of these precautions vomiting 
occurred more frequently especially during the $2^{\text {nd }}$ half of the $1^{\text {st }}$ hour of HD session. In addition, other possible cause of vomiting and nausea was gastroparesis, which occurs commonly in ESRD diabetic patients, although they occurred even in non-diabetic in this study. There were some patients had epigastric pain and central abdominal pain, only few numbers of them had high serum pancreatic enzymes which mostly due to pancreatitis [22].

Feeling of hotness was noticed by significant number of patients' despite of low dialysate temperature $\left(36.5^{\circ} \mathrm{c}\right)$ particularly at the beginning of HD-session. Some of patients felt hotness with increased body temperature without rigor, and patients had hotness, fever and rigor. This could be due to HD- catheter infection, increased respiratory exchange ratio due to feeding or/and reaction to hypoglycemia and/or hypotension that occurred in those patients.

Hypotension during HD session is a common problem. Hypotension reported in significant number of patients in this series, especially during the $1^{\text {st }}$ hour of HD session. Drop of blood pressure might be due to rapid fluid removal, fear and tachycardia, allergic reaction, high intradialytic fluid retention, impaired heart function, blood loss or other unknown reasons. Most of the patients participated in this study had not given history of cardiac problems, and their heart function was reasonably good by ECHO assessment. Patients who had hypotension brought more than $3.5 \mathrm{Kg}$ over their dry weight, and they were having their food during the first hour of HD session. Furthermore, hypotension had been noticed in patients who had vomiting, hotness, fever and rigor and in diabetic patients. This was reported by other researchers $[20,23]$.

Hypoglycemia was not uncommon complication reported in this study. Most of patients who had low RBS were diabetic and had HD by high flux filter. Most of our patients came to HD had not taken breakfast or small snake before they came. ESRD had usually difficulty to keep their blood sugar in normal range. However, some patients had full picture of hypoglycemia, other patients had RBS $50 \mathrm{mg} / \mathrm{dl}$, and they had not any symptoms of hypoglycemia. Most of these patients who had hypoglycemia and its clinical features were diabetic for more than 8 years. It has been claimed that low RBS during HD might be due to an increase in anaerobic use of glucose by erythrocytes [24,25]. In addition, In Libya, up to the September 2018, glucose-free HD concentrate was the only available concentrate; this could be the reason for the increased frequency of hypoglycemia in Libyan patients during HD session.

In this study, we had lost four patients; one patient had tachycardia, and low blood pressure, and then died after 24 hours in medical intensive care unit. Other three patients died suddenly during the session, and their death was mostly due to sudden myocardial infarction and cardiac arrest [20].

In conclusion, vomiting, low RBS, hotness and hypotension are not uncommon during intradialytic period. Early start of HD, suitable dialysate temperature, strict infection control, regular vital signs observation on short time basis, and doing HD with glucose containing dialysate solutions are major issues to decrease these acute HD complications.

\section{Acknowledgment}

The authors would like to thank whole doctors and nurses working at Department of medicine at Tripoli central Hospital specially those who work at dialysis and Intensive care Unit.

\section{References}

1. Abel JJ, Rowntree LG, Turner BB. On the removal of diffusible substances from the circulating blood by means of dialysis. Tran- sections of the Association of American Physicians, 1913. Transfus Sci. 1990; 11: 164-165.

2. Prabhakar J, Singh RG, Singh S, Rathore SS, Choudhary TA. Spectrum of Intradialytic Complications during Hemodialysis and Its Management: A Single-Center Experience. Saudi J Kidney Dis Transpl. 2015; 26: 168-172.

3. Blagg CR. Long-term Complications in Hemodialysis. Saudi J Kidney Dis Transpl. 2001; 12: 487-493.

4. Habas E, Rayani A, Khamaj A. Long-term Complication of Hemodialysis Sebha Medical Journal. 2012; 1: 12-18.

5. Grassmann A, Gioberge S, Moeller S, Brown G. ESRD patients in 2004 global overview of patient numbers, treatment modalities and associated trends. Nephrology, dialysis, transplantation: official publication of the European Dialysis and Transplant Association - European Renal Association. 2005; 20: 2587-2593.

6. Szczech LA, Lazar IL. Projecting the United States ESRD population: issues regarding treatment of patients with ESRD. Kidney International, Supplement. 2004; 66: 3-7.

7. Uta A, Shawish T, Milud N, Mishra A, Ehtuish EF. Outcome of Libyan National Organ Transplantation Program in its third anniversary. JMJ. 2008; 1: 44-50.

8. Kollf W. First clinical experience with the artificial kidney: A dialyzer with a great area. J Am Soc Nephrol. 1997; 8: 1959-1965.

9. USRDS 2010 Annual Data Report: Atlas of Chronic Kidney Disease and End-Stage Renal Disease in the United States. Bathesda: National Institute of Health, National Institute of Diabetes and Digestive and Kidney Disease. 2010.

10. Goleg FA, Kong NC, Sahathevan R. Dialysis-treated end-stage kidney disease in Libya: epidemiology and risk factors. Int Urol Nephrol. 2014; 46: 1581-1587.

11. Alashek WA, McIntyre CW, Taal MW. Epidemiology and etiology of dialysistreated end-stage kidney disease in Libya. BMC Nephrol. 2012; 1-7.

12. Schreiber MJ. Clinical case-based approach to understanding intradialytic hypotension. Am J Kidney Dis. 2001; 38: S37-47.

13. Jansen $\mathrm{PH}$, Veenhuizen $\mathrm{KC}$, Wesseling $\mathrm{Al}$, de Boo $\mathrm{T}$, Verbeek $\mathrm{AL}$. Randomized controlled trial of hydroquinine in muscle cramps. Lancet 1997 ; 349: 528-532.

14. Sherman RA, Daugridas J, Ing TS. Complications during hemodialysis In: Daugridas JT, Blake PG, Ing TS, eds. Handbook of Dialysis, $4^{\text {th }}$ edn. Philadelphia: Lippincott Williams \& Wilkins. 2007; 170-191.

15. Trinh-Trang-Tan MM, Cartron JP, Bankir L. Molecular basis for the dialysis disequilibrium syndrome: Altered aquaporin and urea transporter expression in the brain. Nephrol Dial Transplant. 2005; 20: 1984-1988.

16. Pstein A, Kay G, Plumb V. Considerations in the diagnosis and treatment of arrhythmias in patients with end-stage renal disease. Semin Dial. 1990; 2: $31-37$

17. Remuzzi G. Bleeding in renal failure. Lancet. 1988; i: 1205-1208.

18. Hakim RM, Breillatt J, Lazarus JM, Port FK. Complement activation and hypersensitivity reactions to dialysis membranes. N Engl J Med. 1984; 311: 878-882.

19. Sica DA, Harford AM, Zawada ET. Hypercalcemic hypertension in hemodialysis. Clin Nephrol. 1984; 22: 102-104

20. Bleyer AJ, Russel GB, Satko GB. Sudden and cardiac deaths rates in hemodialysis patients. Kidney Int. 1999; 55: 1553-1559.

21. Singh S, Prakash J, Shukla VK, Sharatchandra Singh LK. Intravenous Catheter associated complications. J Assoc Physicians India. 2010; 58: 194196. 
22. Hou SW, Lee YK, Chen-Yang Hsu CY, Lee CC, Su YC. Increased Risk of Acute Pancreatitis in Patients with Chronic Hemodialysis: A 4-Year Follow-Up Study. PLoS One. 2013; 8: 1-6.

23. Zucchelli P, Santoro A, Zucchala A. Genesis and control of hypertension in hemodialysis patients. Semin Nephrol. 1988; 8: 163-168.

24. Takahashi A, Kubota T, Shibahara N, Terasaki J, Kagitani M, Ueda
$\mathrm{H}$, et al. The mechanism of hypoglycemia caused by hemodialysis. Clin Nephrol. 2004: 62: 362-368

25. Jackson MA, Holland MR, Nicholas J, Lodwick R, Forster D, Macdonald IA Hemodialysis-induced hypoglycemia in diabetic patients. Clin Nephrol. 2000; 54: 30-34.
Austin J Nephrol Hypertens - Volume 6 Issue 1 - 2019

ISSN : 2381-8964 | www.austinpublishing group.com

Habas et al. (C) All rights are reserved
Citation: Habas El, Rayani A, Alkanonie W, Habas A, Alzoukie E, Razeik S, et al. Common Complications during Hemodialysis Session; Single Central Experience. Austin J Nephrol Hypertens. 2019; 6(1): 1078. 